\title{
A Study on the Health Output Effect of Chinese Medical Service Industry Agglomeration Based on Big Data Analysis
}

\author{
Yan Shu $\mathbb{D}^{1},{ }^{1}$ Longxin Lin $(\mathbb{D})^{2}$ and Yueqian $\mathrm{Hu} \mathbb{1}^{3}$ \\ ${ }^{1}$ School of Economics and Management, Guangzhou University of Chinese Medicine, Guangzhou, China \\ ${ }^{2}$ College of Information Science and Technology, Jinan University, Guangzhou, China \\ ${ }^{3}$ School of Business, Guangdong University of Foreign Studies, Guangzhou, China \\ Correspondence should be addressed to Yueqian Hu; 20170401772@gdufs.edu.cn
}

Received 20 August 2020; Revised 13 September 2020; Accepted 21 September 2020; Published 27 October 2020

Academic Editor: Weilin Xiao

Copyright ( 92020 Yan Shu et al. This is an open access article distributed under the Creative Commons Attribution License, which permits unrestricted use, distribution, and reproduction in any medium, provided the original work is properly cited.

\begin{abstract}
The agglomeration health output effect of the medical service industry in the era of big data is an important part of the agglomeration innovation of medical resources. This paper used the regression model of data mining to set up the fixed effect model and system GMM model to study the relationship between the agglomeration of medical service industry and resident's health level, based on the panel data of 31 provinces of China from 2003 to 2017. The results show that the health outcome of the medical industrial agglomeration is positive and different in provinces. The influence of medical service cluster on residents' health level in the eastern region fails the significance test, while the medical service cluster in the central and western regions can significantly improve residents' health level. And, this effect is also related to the characteristics of medical resources, economic development, demographic characteristics, and other heterogeneous factors. On this basis, the paper puts forward policy suggestions to promote the market structure of the medical industry from the aspects of strengthening synergies and policy guidance.
\end{abstract}

\section{Introduction}

In 2018, Paul Zane Pilzer, an American economist, proposed that the healthcare industry is a star industry with a global scale of trillions after the electronic information industry. From the development practice of all countries in the world, the health care industry has become a strong driving force for the growth of national economy. In OECD countries, the added value of the health care industry accounts for $10 \%$ of GDP, while in the United States it has exceeded 17\%, while in China it is only 5\% [1]. With the advancement of a new round of health care reform, the development of health service in China has risen as a national strategy. In October 2016, the "healthy China 2030" planning outline, issued by the State Council, explicitly pointed out that the total scale of China's health service industry will reach 16 trillion yuan by 2030, and the medical and health industry will become the pillar industry of China's national economy. With the development of big data, the most important innovative resources in the healthcare industry will focus on the allocation and utilization of information resources, so the economic benefits of big data in healthcare are becoming increasingly prominent. McKinsey's (2013) The Big Data Revolution in Health Care estimates that big data has reduced health spending in the United States by $\$ 300$ billion to $\$ 450$ billion, equivalent to 12 percent to 17 percent of US health spending in 2011 [2].

As an important branch of medical and health industry, the health output effect of medical service industry agglomeration is an important content of the innovation of health and medical resources agglomeration. There has been fast development of medical services in China since the reform and opening up. According to statistics, the total number of national medical and health institutions increased from 1978 in 170000 to 2017 in 987000, practicing physician per thousand population rose from 1.08 in 1978 to 2.44 in 2017, and medical and health institutions of beds per thousand population from 1.94 in 1978 rose to 5.72 in 2017. However, because the regional imbalance in the development of China's medical service industry still exists, the 
phenomenon of cross-regional medical treatment is increasing, and the medical industry cluster in different regions is significantly different. Will the level of medical industry cluster affect the health level of residents? Does it promote or inhibit the health of residents? What factors influence its performance? The regression analysis method based on data mining technology to study the health output effect of the agglomeration of China's medical service industry will be helpful to promote the agglomeration innovation of China's medical and health resources, which effectively solve the heterogeneous differences in the distribution of regional health resources.

\section{Literature Review}

Industrial cluster is a geographical phenomenon in the dynamic evolution of industry, so scholars at home and abroad have conducted many fruitful researches on this economic phenomenon. However, there are few studies on cluster of medical service industry, especially the literature on the influence of cluster of medical service industry on health. After reviewing the existing literature, it can be summarized into the following aspects.

\subsection{Research on the Essence and Development Mode of} Medical Service Industry. Scholars mainly study the connotation of medical service industry from the aspects of economic impact and medical reform policy. In terms of economic impact, Relman proposed that the medical service industry was a high-profit industry, which not only affected the implementation effect of the national health policy, but also promoted economic growth [3]. DeVol and Koepp measured the cluster degree of health services in the US, and the empirical evidence showed that health services in the US played a significant role in promoting economic development [4]. Zhou and Liu put forward that the medical service industry is an important channel to achieve economic transformation and upgrading and put forward suggestions on developing the medical service industry from the aspects of top-level design, reform, and innovation [5]. Gao pointed out that, in the stage of high-quality economic development, promoting the supply-side reform of the medical service industry is the key to achieving the sick having access to medical care [6].

In terms of medical reform policies, Serrano Ibis analyzed the current situation and characteristics of American medical service industry and discussed the impact of American medical reform on the pharmaceutical industry [7]. Devlin-Foltz et al. pointed out that the social security system plays a leading role in the income level of most American retirees based on the perspective of distribution [8]. Schoen et al. proposed policy recommendations to improve access to medical services and reduce the economic burden of high cost of health services, regarding low-income and disadvantaged groups as the research subjects [9]. Domestic scholars have conducted extensive studies on medical reform policy. For example, Xing focused on medical system reform on public hospitals and proposed that public hospitals are the core carrier of the development of medical service industry [10]. Song et al. studied the allocation of public resources between different hierarchies and regions and pointed out the importance and urgency of hierarchical medical reform [11].

\subsection{Research on the Mechanism of Service Industry Cluster.} Scholars at home and abroad have studied the cluster mechanism of service industry mainly from endogenous mechanism and exogenous mechanism. In endogenous mechanism, firstly, the cluster of service industry reduces the information cost and transaction cost of enterprises, thus gaining advantages in competitive cost (Keeble \& Nachum) [12]. Secondly, the complementary symbiosis is the driving force of service industry cluster; that is, agglomeration between industries within the service industry and between the service industry and other industries can effectively achieve its ultimate goal (Pandit et al.; Bathelt) $[13,14]$.Thirdly, the service industry cluster aims to acquire tacit knowledge. Tacit knowledge cannot be transmitted by traditional means and can only be acquired through close interaction between industries (Zhao et al.) [15]. Fourthly, the aggregation motivation of service industry is the demand for industrial innovation. Through agglomeration, a large-scale innovation network is formed, and the communication between industries can stimulate the application of new technologies and methods (Keeble \& Nachum; Han) $[12,16]$. In exogenous mechanism, most scholars believe that the main reason for service industry cluster is externality, which means that, due to external economies of scale, enterprises can reduce transaction costs by concentrating in geographical regions to improve their competitiveness (Pandit et al.; Breandan \& Timothy; Wang; Zhang et al.; Liu et al.) $[13,17-20]$. In addition, some scholars hold that the motivation of aggregation is the reservoir effect of human resources. The high-quality talents can reduce the search cost of human capital of enterprises and achieve common benefits in the area.

\subsection{Research on the Influence of Medical Service Industry} Cluster on Health. Health was originally a medical problem, but since the 1980s, scholars at home and abroad began to study the relationship between health and economy. Most studies have focused on the impact on health such as medical insurance and health expenditure. Literature studies have focused on the impact of health insurance and health expenditure on the resident health.

In terms of the impact of medical insurance on health, most scholars believe that medical insurance lowers the relative price of medical services to a certain extent and improves the utilization rate of medical services, thus reducing the incidence of some diseases and significantly improving the health conditions of residents (Goldman et al.; Card et al.; Huang and Gan) [21-23]. However, some scholars believe that medical insurance significantly reduces the marginal cost of medical services, but the moral hazard will lead to the waste of medical resources, and the insured's health conditions do not improve significantly (Finkelstein 
\& Mcknight; King et al.; Chen \& Jin) [24-26]. In terms of the impact of health expenditure on health, scholars believe that the allocation of health resources is highly dependent on the government's health expenditure, which can not only guarantee the public welfare of health services, but also improve the effective of health services and the health level of residents (Grossman; Farag et al.; Sun et al.) [27-29]. In the context of rapid supply-side reform of health service industry, social health expenditure develops rapidly and improves the effective supply of health service. As an important part of health financing, social health expenditure, like government health expenditure, has significant health output effect $(\mathrm{Hu})[30]$.

\subsection{Research on the Impact of Big Data on the Medical Service} Industry. At present, domestic and foreign researches on the effect of big data on the health output of the medical service industry are rarely involved, and existing relevant researches mainly focus on the following two aspects. The first one is about the impact of big data on the medical industry. Kayyali et al. studied the impact of big data on the medical industry in the United States and pointed out that many potential values of medical big data are gradually being discovered [31]. Kaggal et al. proposed that the lack of big data analysis technology and the openness of medical big data will seriously hinder the development of medical service industry [32]. Wang et al., taking Jiangsu Province as an example, pointed out that the establishment of big data sharing mechanism for health care is the key [33]. The other one is about the processing technology and risk of medical big data. Raghupathi and Raghupathi pointed out that the biggest difference between the application architecture of medical big data and the traditional medical information architecture lies in distributed computing and information storage [34]. Guo et al. proposed that the service based on medical big data involves the benefit distribution and responsibility sharing of all participants, which may lead to new problems such as the definition of medical responsibility and the prevention of medical accidents [35]. Huang studied the impact of big data technology on medical service system and expounded the innovation and risks that big data technology may bring from the aspects of knowledge, organization, rules, and culture [36].

Scholars at home and abroad mainly focus on the connotation, development model, agglomeration mechanism of the service industry, and the application of big data in the medical field and have made many fruitful research results. However, there are few literatures on the effect of big data on health output of medical service industry agglomeration. Based on the theory of agglomeration economy, this paper uses provincial panel data of China's medical service industry to estimate the degree of agglomeration of medical service industry and conducts an empirical study on the influence mechanism of agglomeration of medical service industry on residents' health under the background of big data.

\section{Research Hypothesis}

3.1. Influence of Medical Service Industry Cluster on Residents' Health. With accelerating trend of urbanization and population aging, the health of residents is threatened of infectious and chronic diseases, so the demand for medical and health services is increasing. Due to the particularity of the medical service market, information asymmetry, and the contradiction between the supply and demand of medical service, the Chinese government implements a relatively strict supervision policy on the medical service market. In the stage of high-quality economic development, the supply of medical services is difficult to meet the diversified and multilevel medical needs. It is too difficult and expensive to see a doctor in China. With the deepening of marketization and reform in the property rights of public hospital, the development of China's medical service industry is characterized by insufficiency and imbalance, and urban-rural gap and regional imbalance are increasingly significant. At the same time, China's medical service industry shows agglomeration phenomenon, which is reflected in medical funds that continue to gather in the eastern coastal areas. The medical service industry cluster has brought about lots of high-quality medical resources, which is conducive to exerting scale effect, improving the accessibility of highquality medical services for residents, and thus improving the health level of residents.

$\mathrm{H1}$ : medical service industry cluster has a positive impact on residents' health level.

\subsection{Influence of Medical Service Industry Cluster on Residents' Health}

3.2.1. Influence of Medical Resources on the Agglomeration of the Medical Service Industry. According to the theory of industrial cluster, industrial economic activities tend to be concentrated in areas with rich sensitive resources. The medical service industry cluster is less affected by natural resource endowment but more affected by high-quality talents. If the medical service industry enterprises in a region attract more high-quality medical technical talents, the transaction cost of the enterprises will decrease and the market scale will expand rapidly, which will further promote the medical service industry cluster and form the accumulation cycle of agglomeration. At the same time, highquality medical technical personnel represent the innovation ability of the region and can produce significant knowledge spillover effect, which will further promote the agglomeration of medical service industry. In China's first-tier cities, medical service enterprises often have the country's firstclass medical technical personnel and the most advanced medical service facilities. Lv pointed out that China's medical resources show a polarization, on the one hand, between rural and urban areas and, on the other hand, between major hospitals in cities and grass-roots health organizations [37]. Major hospitals in big cities have far more medical resources than those in second-tier cities and other regions. 
$\mathrm{H} 2$ : medical resources have a positive impact on the medical service industry cluster and the health of residents.

\subsubsection{Influence of Resident Income on the Medical Service} Industry Cluster. Residents' income directly determines their material living standard. In general, the higher the disposable income is, the more the residents spend on nutrition, exercise, physical examination, and health care, which means that the increase of disposable income can bring more expenditure on medical service and more demand for medical service, thus affecting the agglomeration of medical service industry. Zhang proposed the income health effect and the income effect [38]. Income health effect means the health status of high-income people may be relatively good, and the medical expenditure of high-income people is less when other conditions are similar, while income effect means medical consumption is a normal, and the higher the income is, the more medical services and the more medical expenditure they spend.

The income gap also affects the medical services cluster. On the one hand, the income gap leads to the difference in the demand for medical services between the rich and the poor. The decrease in the investment and expenditure of public goods affects the medical service industry cluster. Krugman pointed out that large differences in people's preferences would lead to the undervaluation of public goods, which would lead to the reduction of public expenditure and increase the difficulty in the implementation of public policies [39]. On the other hand, according to the demand theorem, the increase in income leads to the increase in the demand for medical services, but high-income people take up more medical resources, which will not only reduce the accessibility of medical services for low-income people, but also allocate medical resources to the place with the greatest profit in the market price system. Wei and Gustafsson pointed out that the insufficient public medical expenditure would lead to the higher-income class finding it easier to access medical services. The widening income gap eventually leads to better medical services concentrate in big cities [40].

H3: residents' income has a positive impact on medical service industry cluster and has a positive impact on residents' health.

\section{Empirical Study}

4.1. Empirical Model. According to Grossman's theory of healthy production, health is a commodity jointly produced by a series of factors such as education, income, medical service, and lifestyle. In order to examine the impact of the market structure of the medical service industry on health, this paper takes the agglomeration degree of the medical service industry as an input factor and sets the static panel model as follows:

$$
\text { Health }_{i, t}=\alpha+\beta_{1} L Q_{i, t}+\beta_{2} X_{i, t}+\mu_{i}+\varepsilon_{i, t},
$$

where Health ${ }_{i, t}$, an explanatory variable, is the health level of population. $L Q_{i, t}$, a core explanatory variable, is the degree of agglomeration of medical services. $X_{i, t}$ is a control variable. $\alpha$ is constant term. $\mu_{i}$ is region effect. $\varepsilon_{i, t}$ is random perturbed variable.

The relationship between residents' health and the concentration of medical service industry is complex, and the current health level of residents may be affected by the health level of the previous period. In this paper, residents' health level with a lag of one stage is taken as an explanatory variable, and the dynamic panel model is established as follows:

$$
\text { Health }_{i, t}=\alpha+\beta_{1} \text { Health }_{i, t-1}+\beta_{2} L Q_{i, t}+\beta_{3} X_{i, t}+\mu_{i}+\varepsilon_{i, t},
$$

where, Health Hit-1 $_{\text {is }} 1$ period lag in the health level of population. The other variables are the same.

\subsection{Variable Declaration}

4.2.1. Explained Variable. The explained variable is the level of health of residents $\left(\right.$ Health $\left._{i, t}\right)$.The UN's Millennium Development Goals are to reduce child mortality, improve maternal health, and combat HIV and other diseases. Due to the availability of data, Maternal Mortality Rate (Mmr) is chosen to reflect the health level of the residents. The maternal mortality rate is the number of maternal deaths per 100,000 live births during the year. The higher the value of this negative indicator is, the lower the health level of residents will be.

4.2.2. Explaining Variable. We considered the degree of medical service industry cluster $\left(L Q_{i, t}\right)$. This paper applies the location entropy method to measure the agglomeration degree of medical service industry in China. Location entropy was first proposed by Hargate, which is used in location analysis. Also known as the regional concentration index of production, it is the ratio of ratios. The calculation formula is as follows:

$$
L Q_{i, j, t}=\frac{q_{i, j, t} / q_{i, t}}{q_{i, t} / q_{t}},
$$

where. $L Q_{i, j, t}$ represents the concentration degree of industry $i$ in region $j$ during period $t . q_{i, j, t}$ represents the employment number of industry $i$ in region $j$ during period t. $q_{i, t}$ represents the number of people employed in nationwide $i$ industry during $t$ period. $q_{t}$ represents the number of employed people in the whole country during period $t$. In this paper, $i$ represents the employment in medical service industry, which consists of professional physicians, registered nurses, pharmacist, rural doctors, licensed (assistant) physicians, licensed physicians, registered nurses, pharmacists, and health workers.

The characteristic variable of medical resources is represented by the number of beds in medical institutions per 1,000 population (Bper1000), which reflects the level of medical facilities and services in different regions.

Economic development variables include per capita disposable income and urbanization rate. The population 
proportion index method is generally adopted to measure the urbanization level, that is, the proportion of urban population in the total population.

The demographic characteristics variable refers to the level of education. In this paper, the length of schooling (Edu) is used to indicate that illiteracy is 0 years, primary school education is 6 years, junior high school education is 9 years, senior high school education is 12 years, and junior college education and above are 16 years. In order to weaken the heteroscedasticity of the data, all variables were logarithmically processed.

The balance panel data of 31 provincial regions in China from 2003 to 2017 were adopted in this paper. The data were obtained from China Statistical Yearbook and China Statistical Yearbook of Health and Family Planning.

\section{Quantitative Analysis}

5.1. Descriptive Statistical Analysis. Table 1 shows the variables and descriptive statistical results in the empirical model. The minimum value and maximum value of $\mathrm{Mmr}$ of residents' health level are 1.1 and 399.1, indicating that there are large differences in residents' health level in the sample. The minimum value of $L Q$, the indicator variable of the agglomeration degree of medical service industry, is 0.53 and the maximum value is 3.19 , indicating that there are significant differences in the agglomeration degree of medical service industry in various provinces of China. At the same time, per capita disposable income varies in a larger range, and the standard deviation is as high as 8226 , which shows the regional economic development and its imbalance in China. The above problems also exist in the urbanization rate and the years of schooling (Edu), and the gap between the minimum and maximum values is also large.

5.2. Full Sample Regression of the Influence of the Medical Service Industry Cluster on the Health Level of Residents. Regression methods of panel data generally include mixed regression, fixed effect regression, and random effect regression. Generally, $F$ test is used to judge whether the empirical model should use mixed regression or fixed effect regression, while Hausman test is used to judge whether the empirical model should use fixed effect regression or random effect regression. The empirical test of the sample data shows that both the $F$ value and the Hausman value show that the static panel model (1) should adopt the fixed effect regression method.

In order to avoid the result bias caused by the possible endogeneity problems between variables, instrumental variable method is further introduced for estimation. The estimation methods commonly used in the instrumental variable method are generalized moment estimation (GMM) and two-stage least square method (2SLS). The assumptions of generalized moment estimation (GMM) are more lenient, so it is not necessary to assume the same variance, but to use instrumental variables to estimate parameters, which can effectively solve the endogenous problem. System-GMM estimation method introduces the horizontal equation on the difference-GMM estimation method and takes the lag difference variable as the instrumental variable, which improves the effectiveness of the estimation results. In this paper, residents' health level lagged by one stage was added into the static panel model, and the dynamic panel model (2) above was constructed, and the robustness test was carried out by applying the system GMM estimation method. Specific regression results are shown in Table 2:

The validity test of system GMM estimation mainly includes constraint test of overidentification (Sargan test or Hansen test) and sequence correlation test (AR(1) and $\mathrm{AR}(2)$ ). The former is used to test the validity of instrumental variables in sample estimation. The latter is used to verify the existence of sequence correlation. The system GMM estimation method allows the existence of first-order difference sequence correlation, but it does not allow the existence of second-order difference sequence correlation. The regression results in Table 2 show that the Sargan test $P$ value of the dynamic panel model (2) is 0.669 , indicating that the selection of instrumental variables is effective, and the $P$ value of the $\operatorname{AR}(2)$ test is 0.269 , indicating that there is no second-order sequence correlation between the residuals after the first-order difference. Therefore, it is reasonable to judge that the system GMM estimation method is adopted.

The fixed effect regression in Table 2 is consistent with the sign of each coefficient in the system GMM regression, and individual coefficient estimates become more significant, which also indicates the robustness of the estimated results. According to the GMM estimation results of the system, the estimated coefficient of the agglomeration degree of the medical service industry is -0.056 , which is significant at the $10 \%$ level. This result confirms hypothesis $\mathrm{H1}$; the higher the agglomeration degree of the medical service industry, the lower the maternal mortality rate, indicating the higher the health level of residents. This is because the agglomeration of medical service industry has brought a large number of high-quality medical resources and advanced medical equipment, which contributes to a more effective allocation of medical resources and the realization of scale effect. The estimated coefficient of the number of beds in medical institutions per 1,000 population is -0.168 , which is significant at the $1 \%$ level, indicating that the higher the number of beds in medical institutions per 1,000 population, the lower the maternal mortality rate. This result confirms hypothesis $\mathrm{H} 2$. The reasons are as follows. The more medical resources, the better the agglomeration of medical service industry and the better the accessibility of medical services and the lower the probability of residents not seeking medical treatment due to illness, which is conducive to improving the health level of residents.

The estimated coefficient of per capita disposable income is -0.200 , which is significant at the level of $5 \%$, indicating that the higher the per capita disposable income is, the higher the residents' health level is, confirming hypothesis H3. This result shows that the higher the level of disposable income of residents, the greater the demand for medical services and the greater the expenditure on medical services, which promotes the agglomeration of medical services to a 
TABLE 1: Descriptive statistics of variables.

\begin{tabular}{|c|c|c|c|c|c|}
\hline & Variable & Mean & SD & Mini & Max \\
\hline \multicolumn{6}{|l|}{ Explained variable } \\
\hline & $\mathrm{Mmr}$ & 31.796 & 41.373 & 1.1 & 399.1 \\
\hline \multicolumn{6}{|l|}{ Explaining variable } \\
\hline & LQ & 1.124 & 0.411 & 0.531 & 3.194 \\
\hline & Bper1000 & 3.935 & 1.372 & 1.48 & 7.55 \\
\hline & Income & 17227.83 & 8226.242 & 6530.48 & 58988 \\
\hline & Urban & 50.815 & 14.958 & 20.21 & 89.6 \\
\hline & Edu & 8.519 & 1.222 & 3.738 & 12.5 \\
\hline
\end{tabular}

TABLE 2: Full sample regression of the influence of medical service agglomeration on residents' health level.

\begin{tabular}{lccc}
\hline Variables & $(1) \mathrm{FE}$ & $(2) \mathrm{RE}$ & $(3) \mathrm{GMM}$ \\
\hline L. health & & & $0.843 * * *$ \\
& & & $(9.84)$ \\
LQ & -0.096 & -0.076 & $-0.056 *$ \\
& $(-1.05)$ & $(-0.88)$ & $(-1.82)$ \\
Bper1000 & -0.006 & $-0.156 *$ & $-0.168 * * *$ \\
& $(-0.05)$ & $(-1.84)$ & $(-2.67)$ \\
Income & $-0.441 * * *$ & $-0.435 * * *$ & $-0.200 * *$ \\
& $(-6.53)$ & $(-6.46)$ & $(-2.37)$ \\
Urban & $-2.389 * * *$ & $-1.886 * *$ & -0.102 \\
& $(-7.44)$ & $(-8.06)$ & $(-0.47)$ \\
Edu & $-0.715 *$ & $-0.634 *$ & $-0.199 * *$ \\
& $(-1.94)$ & $(-1.95)$ & $(-2.38)$ \\
cons & $18.102 * * *$ & $16.119 * * *$ & $2.935 * *$ \\
$R^{2}$ & $(16.24)$ & $(22.47)$ & $(2.01)$ \\
F & 0.778 & 0.774 & \\
Hausman & $25.67 * * *$ & & \\
AR $(1) P$ value & & $30.18 * * *$ & \\
AR $(2)$ 的 $P$ value & & & 0.000 \\
Sargan value for & & & 0.269 \\
inspection & & & 0.669 \\
Obs & 465 & 465 & 434 \\
\hline
\end{tabular}

Note: (1) FE represents fixed effect model, FE represents random effect model, and GMM represents system GMM estimation of dynamic panel model; (2) FE estimation and GMM estimation are both $T$ value in brackets, and Re estimation is $Z$ value in brackets; (2) symbols $*, * *$, and $* * *$, respectively, represent the significance level of $10 \%, 5 \%$, and $1 \%$.

certain extent, which confirms the above income effect. Urbanization rate has a positive influence on residents' health level, but it fails to pass the significance test. This may be due to the fact that, on the one hand, the acceleration of urbanization has brought an increase in the number of urban residents, and medical resources are gradually inclined to populated areas. The improvement of residents' access to medical services contributes to the improvement of their health level. On the other hand, urban work pressure and life pressure are relatively high, and residents may have a significantly higher incidence of disease and a lower level of health due to higher stress. The improvement of education level has significantly improved the health level of residents. This is because the higher the education level of residents, the more initiative to obtain health information. At the same time, the improvement of health awareness is conducive to increasing the number of health checks, early detection, and early treatment of diseases. Therefore, the higher the level of education, the greater the effect of healthy production function.

\subsection{Regional Difference Analysis of the Influence of Medical} Service Cluster on Residents' Health Level. To investigate whether there are regional differences in the health output effect of medical service agglomeration, the whole sample was divided into eastern, central, and western regions. Table 3 shows the regression results of the influence effect of the agglomeration of medical service industry on the health level of residents in the subregion. $F$ test value and Hausman test say the eastern, central, and western regions are suitable for the fixed effects regression model; to estimate the robustness of results, further to the eastern, central, and western regions, respectively, system GMM estimation, the sample data of AR (1) and AR (2), and Sargan test $P$ values show that a systematic GMM estimation method is effective and feasible.

It can be seen from Table 3 that the agglomeration degree of medical service industry in eastern China has a positive impact on the health level of residents, but it fails the significance test. The agglomeration degree of medical service industry in central and western China significantly improves the health level of residents. As the economic level of eastern region is more developed, with leading medical services and diminishing the marginal effect of health, medical service industry cluster is not the key to improve the health level of residents. The economic level of central and western region is less developed, which the medical service level is relatively backward, so the medical service industry cluster brings an increasing marginal effect in health. The effect of the number of beds per 1,000 people in the eastern region on the health of residents did not pass the significance test, but in the central and western regions, the more the beds per 1,000 people in the medical institutions, the better the health of residents. The reason is that the eastern region has abundant medical resources, while the central and western regions are in short supply. The agglomeration of medical service industry in the central and western regions brings a larger scale effect of medical resources and plays a more important role in improving the health level of residents. The impact of per capita disposable income on residents' health in eastern, central, and western 
TABLE 3: Regional differences of the influence of medical service agglomeration on residents' health level.

\begin{tabular}{|c|c|c|c|c|c|c|}
\hline \multirow{2}{*}{ Variable } & \multicolumn{2}{|c|}{ Eastern region } & \multicolumn{2}{|c|}{ Central region } & \multicolumn{2}{|c|}{ West region } \\
\hline & $\mathrm{FE}$ & GMM & $\mathrm{FE}$ & GMM & $\mathrm{FE}$ & GMM \\
\hline L. health & & $\begin{array}{c}0.639^{* * *} \\
(8.99)\end{array}$ & & $\begin{array}{c}0.793^{* * *} \\
(11.71)\end{array}$ & & $\begin{array}{c}0.825^{* * *} \\
(17.71)\end{array}$ \\
\hline LQ & $\begin{array}{l}-0.209 \\
(-0.92)\end{array}$ & $\begin{array}{l}-0.027 \\
(-0.13)\end{array}$ & $\begin{array}{l}-0.004 \\
(-0.02)\end{array}$ & $\begin{array}{c}-0.036^{*} \\
(-1.85)\end{array}$ & $\begin{array}{l}-0.137 \\
(-1.31)\end{array}$ & $\begin{array}{c}-0.062^{*} \\
(-1.84)\end{array}$ \\
\hline Bper1000 & $\begin{array}{l}0.301 \\
(1.09)\end{array}$ & $\begin{array}{l}-0.073 \\
(-0.42)\end{array}$ & $\begin{array}{l}-0.122 \\
(-0.62)\end{array}$ & $\begin{array}{c}-0.173^{*} \\
(-1.82)\end{array}$ & $\begin{array}{c}-0.551^{* * *} \\
(-3.28)\end{array}$ & $\begin{array}{c}-0.077^{* *} \\
(-2.21)\end{array}$ \\
\hline Income & $\begin{array}{l}-0.271 \\
(-1.51)\end{array}$ & $\begin{array}{c}-0.335^{*} \\
(-1.91)\end{array}$ & $\begin{array}{c}-0.471^{* * *} \\
(-3.96)\end{array}$ & $\begin{array}{c}-0.357^{* * *} \\
(-3.10)\end{array}$ & $\begin{array}{c}-0.468^{* * *} \\
(-6.25)\end{array}$ & $\begin{array}{c}-0.160^{* *} \\
(-2.07)\end{array}$ \\
\hline Urban & $\begin{array}{c}-3.064^{* * *} \\
(-3.23)\end{array}$ & $\begin{array}{c}-0.746^{*} \\
(-1.96)\end{array}$ & $\begin{array}{c}-2.484^{* * *} \\
(-5.83)\end{array}$ & $\begin{array}{l}-0.087 \\
(-0.35)\end{array}$ & $\begin{array}{c}-1.435^{* * *} \\
(-3.53)\end{array}$ & $\begin{array}{l}-0.022 \\
(-0.17)\end{array}$ \\
\hline Edu & $\begin{array}{c}-2.280^{* *} \\
(-2.17)\end{array}$ & $\begin{array}{c}-1.323^{*} \\
(-1.79)\end{array}$ & $\begin{array}{l}-0.503 \\
(-0.68)\end{array}$ & $\begin{array}{c}-0.174^{* *} \\
(-2.30)\end{array}$ & $\begin{array}{l}-0.142 \\
(-0.40)\end{array}$ & $\begin{array}{c}-0.554^{* * * *} \\
(-2.67)\end{array}$ \\
\hline _cons & $\begin{array}{c}22.426^{* * *} \\
(7.20)\end{array}$ & $\begin{array}{c}4.400^{* * *} \\
(3.34)\end{array}$ & $\begin{array}{c}17.932^{* * *} \\
\quad(8.61)\end{array}$ & $\begin{array}{c}3.773^{* *} \\
(2.19)\end{array}$ & $\begin{array}{c}13.799^{* * *} \\
(10.08)\end{array}$ & $\begin{array}{c}3.171^{* * *} \\
(3.40)\end{array}$ \\
\hline$R^{2}$ & 0.591 & & 0.856 & & 0.903 & \\
\hline $\mathrm{F}$ & $14.73^{* * *}$ & & $13.85^{* * *}$ & & $35.97^{* * *}$ & \\
\hline Hausman & $14.25^{* *}$ & & $14.46^{* *}$ & & $26.21^{* * *}$ & \\
\hline AR(1)'s value & & 0.069 & & 0.003 & & 0.012 \\
\hline $\operatorname{AR}(2)$ 's value & & 0.287 & & 0.185 & & 0.424 \\
\hline Sargan $P$ value for insection & & 0.455 & & 0.740 & & 0.758 \\
\hline Obs & 165 & 154 & 120 & 112 & 180 & 168 \\
\hline
\end{tabular}

Note: (1) FE estimation and GMM estimation are both Tvalues in brackets; (2) symbols ${ }^{*},{ }^{* *}$, and ${ }^{* * *}$, respectively, represent the significance level of $10 \%, 5 \%$, and $1 \%$.

regions has a significant promoting effect, and high income contributes to the improvement of residents' health level, for the same reasons as in the full sample test. The promotion effect of urbanization rate on the residents' health in eastern regions is more significant than the central and western regions because in the eastern region, urbanization rate is higher, attracting a large number of population and increasing higher medical service demand. At the same time, the improvement of urbanization rate has brought more medical resources and the increase of the medical service accessibility to improve the health level of the residents. In eastern, central, and western regions, years of education have a significant effect on the health of residents, which is consistent with the full sample regression.

\section{Conclusion}

An outline for the "Healthy China 2030" initiative proposed that health is the basic condition for economic and social development. Previous studies have focused on the health output effect and comparative analysis of medical input, but few have discussed the health output effect of medical industrial structure. Based on Grossman's healthy production function, using China's provincial data from 2003 to 2017, this paper studies the health output effect of medical service industry agglomeration with full sample regression and regional difference, drawing the following conclusions: (1) using fixed effects, random effects, and system GMM method to analyze the sample, the result showed that medical service significantly promoted the residents to improve the level of health. However, there are significant regional differences in the health output effect of medical service industry cluster. The medical industry cluster in central and western regions has significantly improved the health level of residents, while the effect in eastern regions has not passed the significance test. (2) Considering other control variables, this paper found that the medical institution beds per thousand population to promote the health level of residents in the sample, central, and western regions of the country's samples passed the test of significance; personal disposable income and education level of the improvement of residents' health passed the test of significance in all samples and regional samples. While the health effects of urbanization rate in the national sample, central, and western regions sample are not by significance test, the eastern part of the effect is significant.

Based on the empirical research results, this paper proposes the following policy recommendations.

First, strengthen the construction of medical and health big data application system and promote the aggregation of advantageous resources in the medical service industry. To remove data barriers, government should promote the data sharing, data mining, and application of health big data based on the regional population health information platform. Standardize the management of medical and health big data, give full play to the resource optimization function of big data technology, improve the coordination and comprehensiveness of the medical service industry, enhance the accessibility of high-quality medical resources, and promote the aggregation of advantageous resources of the medical service industry.

Second, use regional synergy and promote structure optimization of the medical industry. In central and western regions where the development of medical service industry is 
not comprehensive, it is necessary to play to the ability of medical industry cluster to optimize the allocation of medical resources and improve the efficiency, so as to strengthen the scale effect of medical service industry cluster. In eastern region, where medical resources are relatively abundant, the technical level should be improved, and the regional gradient transfer and radiation range should be promoted, so as to improve the health of the residents.

Third, the government needs to strengthen policy guidance to adapt to local conditions and to intensify policy support in central and western areas, through preferential tax credit and financial policies to strengthen the supervision function of government, based on the goal of balanced development of medical resources among regions in China. At the same time, aided by private capital to improve the construction of medical facilities, we can improve the health of the residents and gradually narrow the development gap with the eastern region.

\section{Data Availability}

The data used to support the findings of this study are available from the corresponding author upon request.

\section{Conflicts of Interest}

The authors declare there are no conflicts of interest regarding the publication of this paper.

\section{Acknowledgments}

The authors acknowledge the Philosophy and Social Science Planning Project of Guangdong Province (Grants: GD18XYJ24 and 2019GXJK088), Humanity and Social Science foundation of Guangzhou University of Chinese Medicine (Grant: 2020SKZD07), Lancang-Mekong Cooperation Special Fund in 2020, and the Philosophy and Social Science Researching Colleges and Universities in Guangdong Province.

\section{References}

[1] Y.-f. Liu and Zhen Wang, "The development model of health management in USA and its experiences for China," Asiapacific Economic Review, vol. 3, pp. 75-81, 2016.

[2] McKinsey Consulting, The Big Data Revolution in Health Care, McKinsey Consulting, New York, NY, USA, 2013.

[3] A. S. Relman, "The new medical-industrial complex," New England Journal of Medicine, vol. 303, no. 17, pp. 963-970, 1980.

[4] R. C. DeVol and R. Koepp, America's Health Care Economy, Milken Institute, Santa Monica, CA, USA, 2003.

[5] X. Zhou and J. Liu, "Progress, problems and prospects of China's medical service industry reform," Price:Theory \& Practice, vol. 5, pp. 5-11, 2018.

[6] C. Gao, "The path choice of the development and governance of medical services in the stage of high-quality development," Social Science Front, vol. 5, pp. 222-229, 2019.

[7] S. Serrano Ibis, The World's Health Care Crisis-1:the united states' Leadership, pp. 3-28, World's Health Care Crisis, Geneva, Switzerland, 2011.
[8] S. Devlin-Foltz, A. M. Henriques, and J. E. Sabelhaus, "Is the U.S. retirement system contributing to rising wealth inequality?," Journal of the Social Sciences, vol. 6, pp. 59-85, 2016.

[9] C. Schoen, K. Davis, A. Willink, and C. Buttorf, A Policy Option to Enhance Access and Affordability for Medicare's Low-Income Beneficiaries, pp. 1-15, Commonwealth Found, London, UK, 2018.

[10] W. Xing, "Practice exploration and policy thinking on the development of health service industry," Macroeconomic Management, vol. 6, pp. 29-31, 2014.

[11] X. Song, W. Deng, P. Zhou, S. Zhang, J. Wan, and Y. Liu, "Spatial equity and influences of two-level public healthcare resources: A background to hierarchical diagnosis and treatment reform in China," Acta Geographica Sinica, vol. 6, pp. 1178-1189, 2019.

[12] D. Keeble and L. Nachum, "Why do business ser vice firms cluster? small consultancies, clustering and decentralization in London and southern England," Transactions of the Institute of British Geographers, vol. 1, pp. 67-90, 2001.

[13] N. R. Pandit, G. A. S. Cook, P. G. M. Swann, and G. M. Peter Swann, "The dynamics of industrial clustering in British financial services," The Service Industries Journal, vol. 21, no. 4, pp. 33-61, 2001.

[14] H. Bathelt, "The Re-emergence of a media industry cluster in leipzig," European Planning Studies, vol. 10, no. 5, pp. 583-611, 2002.

[15] S. X. B. Zhao, L. Zhang, and D. T. Wang, "Determining factors of the development of a national financial center: the case of China," Geoforum, vol. 35, no. 5, pp. 577-592, 2004.

[16] M. Han, Research on the Clustering Development of Producer Services Based on the Perspective of Interaction with Manufacturing, Science-Technology and Management, Palaiseau, France, 2009.

[17] B. Ó hUallacháin and T. F. Leslie, "Producer services in the urban core and suburbs of phoenix, Arizona," Urban Studies, vol. 44, no. 8, pp. 1581-1601, 2007.

[18] X. Wang, "Employment absorption, industry agglomeration and the development of producer service sector," Collected Essays on Finance and Economics, vol. 1, pp. 15-19, 2011.

[19] Y. Zhang, Y.-J. Pu, and L.-T. Chen, "Urbanization and service industry agglomeration-a view based on system coupling interaction," China Industrial Economics, vol. 6, pp. 57-69, 2013.

[20] J.-y. Liu, M. Wang, J.-f. Li, and W.-z. Wang, "Literature review of agglomeration on producer services," Journal of Chongqing University of Technology(Social Science), vol. 7, pp. 34-39, 2014.

[21] D. P. Goldman, J. Bhattacharya, D. F. McCaffrey et al., "Effect of insurance on mortality in an HIV-positive population in care," Journal of the American Statistical Association, vol. 96, no. 455, pp. 883-894, 2001.

[22] D. Card, C. Dobkin, and N. Maestas, "Does medicare save lives?*," Quarterly Journal of Economics, vol. 124, no. 2, pp. 597-636, 2009.

[23] F. Huang and L. Gan, "Excess demand or appropriate demand? - health insurance, medical care and mortality of the elderly in urban China," Economic Research Journal, vol. 45, no. 06, pp. 105-119, 2010.

[24] A. Finkelstein and R. McKnight, "What did medicare do? the initial impact of medicare on mortality and out of pocket medical spending," Journal of Public Economics, vol. 92, no. 7, pp. 1644-1668, 2008. 
[25] G. King, E. Gakidou, K. Imai et al., "Public policy for the poor? a randomised assessment of the Mexican universal health insurance programme," The Lancet, vol. 373, no. 9673, pp. 1447-1454, 2009.

[26] Y. Chen and G. Z. Jin, "Does health insurance coverage lead to better health and educational outcomes? evidence from rural China," Journal of Health Economics, vol. 31, no. 1, pp. 1-14, 2012.

[27] M. Grossman, "On the concept of health capital and the demand for health," Journal of Political Economy, vol. 80, no. 2, pp. 223-255, 1972.

[28] M. Farag, A. K. Nandakumar, S. Wallack, D. Hodgkin, G. Gaumer, and C. Erbil, "Health expenditures, health outcomes and the role of good governance," International Journal of Health Care Finance and Economics, vol. 13, no. 1, pp. 33-52, 2013.

[29] Y.-lin Sun, Hu-wei Wen, and H.-feng Xu, "Analysis on health production effectiveness of government health expenditure: based on the perspective of international comparison," Chinese Health Economics, vol. 35, no. 3, pp. 66-67, 2016.

[30] C. Hu, "The impact of social health expenditure on macro health level and its regional differences," Chinese Health Economics, vol. 6, pp. 77-78, 2016.

[31] B. Kayyali, D. Knott, and S. V. Kuiken, The Big-Data Revolution in US Health Care: Accelerating Value and Innovation, Mc Kinsey \& Company, New York, NY, USA, 2013.

[32] V. C. Kaggal, R. K. Elayvilli, and S. Mehrabi, "Toward a learning health-care system-knowledge delivery at the point of care empowered by big data and NLP," Biomed Inform Insights, vol. 8, pp. 13-22, 2016.

[33] J. Wang, K. Leng, and H. Lu, "Study on the innovation of WIT120 medical service mode based on "Internet+"," Journal of Nanjing Medical University(Social Sciences), vol. 2, pp. 84-87, 2020.

[34] W. Raghupathi and V. Raghupathi, "Big data analytics in healthcare: promise and potential," Health Information Ence \& Systems, vol. 2, no. 1, p. 3, 2014.

[35] X. Guo, X. Zhang, X. Liu, and V. Doug, "eHealth service management research in the big data era:challenges and future directions," Journal of Management Science, vol. 30, no. 1, pp. 3-14, 2017.

[36] N. Huang, "The elemnt modality of medical service system under the background of the big data: evolution, anomie and construction," Social Sciences in Ningxia, vol. 219, no. 1, pp. 113-119, 2020.

[37] G. Lv, "From polarization to equilibrium allocation-a path to integrate urban and rural health care resources," Economic Management Journal, vol. 31, no. 12, pp. 155-159, 2009.

[38] C. Zhang, "Empirical analysis on impact of health change on labor supply and income," Economic Review, vol. 4, pp. 79-88, 2011.

[39] P. Krugman, "The spiral of inequality," pp. 44-49, Mother Jones, San Francisco, CA, USA, 1996.

[40] Z. Wei and B. Gustafsson, "Inequity in financing China's healthcare," Economic Research Journal, vol. 12, pp. 26-34, 2005. 